\title{
Vitamin E and Gluthathion as Antioxidant in Liquid Preservation of Semen: A Review
}

\author{
Archana Sarangi ${ }^{1}$, Anuradha Verma ${ }^{2}$, Ram N. Patel ${ }^{2}$, Adya P. Rath ${ }^{3}$, \\ Subhasish Sahu ${ }^{4 *}$, Meenakshi Virmani ${ }^{5}$ and Pooja Devi ${ }^{1}$ \\ ${ }^{1}$ Division of Animal Physiology, NDRI, Karnal, Haryana, India \\ ${ }^{2}$ Division of LPM, NDRI, Karnal, Haryana, India \\ ${ }^{3}$ Department of Veterinary Pathology, GADVASU, Ludhiana, Punjab, India \\ ${ }^{4}$ Department of LPM, ${ }^{5}$ Department of VPB, LUVAS, Hisar, Haryana, India
}

*Corresponding author

\section{A B S T R A C T}

Keywords

Antioxidant, Vit-E,

Glutathion,

Preservation,

Semen

Article Info

Accepted:

12 March 2018

Available Online:

10 April 2018
For improvement of genetic program in animal, artificial insemination (AI) with liquid or frozen semen and quality of semen plays a major role for it. Sperm cells have a high content of polyunsaturated fatty acids in their membranes, and they lack a significant cytoplasmic component containing antioxidants. Therefore, they are susceptible to lipid peroxidation by the action of the reactive oxygen species (ROS). It results in the inhibition of both sperm ATP production and sperm movement, particularly forward progression. The addition of vitamin $\mathrm{E}$ and glutathione, as primary antioxidants to the semen extender prevented the loss of sperm motility by inhibition of lipid peroxidation caused by ROS in chilled boar spermatozoa.

\section{Introduction}

Spermatozoal membrane is rich in polyunsaturated fatty acid (PUFA) and is easily damaged by reactive oxygen species (ROS) or membrane lipid peroxide ion (Silva, 2006). The equilibrium between the amount of ROS produced and scavenged is related with the gamete cell stability and damage. Reactive oxygen species reduce the sperm freezing potential, dysfunction the sperm by lipid peroxidation and affect the cell membrane integrity. These changes finally alter the cytological parameters of semen making them incompetent to fertilize with the ova (Budai et al., 2014). The ROS can be neutralized by antioxidants which serve as defense mechanism against the lipid peroxidation of semen and help in maintaining sperm motility and viability.

Their addition into semen extenders have been reported to improve semen quality in animals Bucak and Ateşşahin (2008). 


\section{Liquid preservation of semen}

Use of liquid semen cooled to room temperature, to intermediate temperatures $\left(+16-20^{\circ} \mathrm{C}\right)$ or chilled $\left(+5^{\circ} \mathrm{C}\right)$ dominates in some livestock species. During liquid preservation of semen, damage to sperm cells occurs during the transportation, handling of semen, concentration of extender and reactive oxygen species etc. Addition of antioxidants into semen extenders have been reported to improve semen quality in boar (Satorre et al., 2007), bull (Bilodeau et al., 2001), stallion (Almeida and Ball, 2005), dog (Michael et al., 2007), cat (Thuwanut et al., 2010) and goat (Sinha et al., 1996).

\section{Oxidative stress and reactive oxygen species}

Oxidative stress is a condition associated with an increased rate of cellular damage induced by oxygen and oxygen derived oxidants commonly known as ROS. Oxidative stress is associated with lipid peroxidation of the sperm outer membrane which leads to loss of sperm motility (Urata et al., 2001) decreased fertilization capacity (Aitken, 1994) and increased chromatin damage (Aitken and Krausz, 2001). ROS represent a broad category of molecules that indicate the collection of radicals (hydroxyl ion, superoxide, nitric oxide, peroxyl, etc.) and non-radicals (ozone, single oxygen, lipid peroxides, hydrogen peroxide) and oxygen derivatives (Agarwal and Prabakaran, 2005).

Mammalian spermatozoa are rich in poly unsaturated fatty acids that make them very susceptible to production of ROS (free radical), induced peroxide damage (Sikka et al., 1982). The production of ROS by sperm is a normal physiological process, but an imbalance between ROS generation and scavenging activity is detrimental to the sperm and associated with male infertility
(Sikka, 1996). ROS induces peroxidation of critical thiol group in protein which alters the structure and function of spermatozoa and make them susceptible to macrophage attack, (Alverez and Story, 1989; Sharma and Agarwal, 1996).

Spermatozoa are capable of generating controlled low amount of endogenous ROS that play significant role in inducing sperm capacitation, acrosomal reaction and acquisition of sperm fertilizing ability (Sikka, 1996). But the high level of ROS endangered the sperm motility, viability and function by interacting with membrane lipids, protein and nuclear, mitochondrial DNA (Aitken and Clarkson, 1987). Involvement of seminal leukocytes with the reactive oxygen species, alter the mitochondrial membrane potential lead to damage of DNA in the human spermatozoa (Lobascio et al., 2015). Mitochondrial permeability transition increases reactive oxygen species production and induces DNA fragmentation in human spermatozoa (Treulen et al., 2015). Hydrogen peroxide appears to be the primary ROS responsible for sperm membrane damage (Alverez and Storey, 1989). It is believed that sperm viability is reduced upto $50 \%$ after the freeze-thawing process (Watson, 1995; Kalthur et al., 2011).

\section{Types of antioxidants used in preservation of semen}

An antioxidant that reduces oxidative stress and improves sperm motility could be useful in the management of male infertility (Bansal and Bilaspuri, 2008). Various antioxidants and antioxidant enzymes have been used to prevent oxidative damage to spermatozoa (Kim and Parthasarathy, 1998). Non enzymatic antioxidants are also known as synthetic antioxidants that include vitamins such as vitamin $\mathrm{C}$, vitamin $\mathrm{E}$ and minerals like zinc, taurine, hypotaurine, and 
glutathione can reduce oxidative stress in female reproduction (Agarwal et al., 2005).

\section{Vitamin E as an antioxidant}

Cryoprotectants and thawing procedure are associated with significant reduction in sperm motility induced by ROS and that effect can be avoided by adding vitamin $\mathrm{E}$ at different doses to the extender at rates like 5 milli mole/ 2.5 milli mole and 10 milli mole concentration (Sharma et al., 1996). Vitamin $\mathrm{E}$ is believed to be the primary component of the antioxidant system of spermatozoa (Surai et al., 1998). In vitro studies shown that vitamin $\mathrm{E}$ is a potent chain breaking antioxidant, that scavenge intermediate peroxyl and alkoxyl radicals in protecting spermatozoa against endogenous oxidative membrane damage and it appears to have a dose dependant protective effect (Agrawal et al., 2005). The concentration of vitamin $\mathrm{E}$ also reduces the MDA by 10-20 percent. Cerolini et al., (2000) used vitamin E as a potent chain breaking antioxidant for prevention of oxidative damage on boar sperm cell membrane in semen maintained in liquid state. The $\alpha$-tocopherol concentration may be conditioning the cryopreserved boar sperm functionality. The addition of antioxidants could be useful to reduce oxidative stress, thus improving the functionality of cryopreserved boar spermatozoa. Kalthur et al., (2011) supplemented vitamin E @ $5 \mathrm{mM}$ and observed significant improvement in the postthaw motility and DNA integrity in normozoospermic and asthenozoospermic semen samples.

\section{Glutathione as an antioxidant}

The spermatozoa are readily undergoing lipid peroxidation, particularly in the presence of oxygen. Addition of antioxidant like glutathione (GSH) might have beneficial effects like sperm motility in frozen bull semen. GSH plays important roles as protective agents against ROS-induced damages in many cell types (Halliwell and Gutteridge, 1998). GSH protects the spermatozoa from oxidative damage by inhibiting the lipid peroxidation process (Foote et al., 2002). GSH also helps in maintaining the integrity of normal acrosome (Sinha et al., 1996) and stabilizes the plasma lemma of spermatozoa and increases motility (El-kon and Darwish, 2011). It has been reported that, addition of antioxidant such as GSH to equine semen (Aurnich et al., 1997; Baumber et al., 2003) has shown to protect sperm against the harmful effects of ROS.

\section{References}

Agarwal, A. and Prabakaran, S.A. 2005. Mechanism, measurement, and prevention of oxidative stress in male reproductive physiology. Journal of Reproduction fertile. 333: 6-67.

Agarwal, A., Gupta, S. and Sharma, R.K. 2005. Role of oxidative stress in female reproduction. Reproductive Biology and Endocrinology. vol. 3, articl 28.

Aitken, R.J. 1994. A free radical theory of male infertility. Reproduction Fertility and Development. 6: 19-23.

Aitken, R.J. and Clarkson, J.S. 1987. Cellular basis of defective sperm function and its association with the genesis of reactive oxygen species by human spermatozoa. Journal of Reproduction fertile. 84: 674679.

Aitken, R.J. and Krausz, C. 2001. Oxidative stress, DNA damage and the chromosome. Reproduction. 122: 497 506.

Almeida, J. and Ball, B.A. 2005. Effect of alpha-tocopherol and tocopherol succinate on lipid peroxidation in equine spermatozoa. Animal Reproduction Science. 87: 321-337. 
Alvarez, J.G. and storey, BT. 1989. Role of glutathione peroxidase in protecting mammalian spermatozoa from loss of motility caused by spontaneous lipid peroxidation. Gamete Research. 23:7790.

Aurnich, J.E., Schonherr, U., Hoppe, H. and Aurnich, C. 1997. Effect of antioxidants on motility and membrane integrity of chilled stored stallion semen. Theriogenology. 48: 185-192.

Bansal, A.K. and Bilaspuri, G.S. 2008. Effect of manganese on bovine sperm motility, viability, and lipid peroxidation in vitro. Animal Reproduction CBRA. 5: 90-96.

Baumber, J., Ball, B.A., Linfor, J.J. and Mejers, S.A. 2003. Reactive oxygen species and cryopreservation promote DNA fragmentation in equine spermatozoa. J. Androl. 24: 621-628.

Bilodeau, J.F., Blanchette, S., Gagnon, C. and Sirard, M.A. 2001. Thiols prevent $\mathrm{H}_{2} \mathrm{O}_{2}$-mediated loss of sperm motility in cryopreserved bull semen. Theriogenology. 56: 275-286.

Bucak, M.N. and Ateşşahin, A. 2008. Effect of anti-oxidants and oxidative stress parameters on ram semen after the freeze-thawing process. Small Ruminant Research. 75:128-134.

Budai, C., Egerszegi, I., Olah, J., Javor, A. and Kovacs, A. 2014. The Protective Effect of Antioxidants on Liquid and Frozen Stored Ram Semen - Review. Animal Science and Biotechnologies. 47 (1):

Cerolini, S., Maldjian, A., Surai, P., Noble, R. 2000. Viability susceptibility to peroxidation and fatty acid composition of boar semen during liquid storage. Anim. Reprod. Sci., 58: 99-111.

El-kon, I.I. and Darwish, S.A. 2011. Effect of Glutathione (GSH) on Microscopic Parameters and DNA Integrity in Egyptian Buffalo Semen during Liquid and Frozen Storage. Journal of
Reproduction and Infertility. 2 (3): 3240.

Foote, R.H., Brockett, C.C. and Kaproth, M.T. 2002. Motility and fertility of bull sperm in whole milk extender containing antioxidant. Animal Reproduction Science. 71: 13-23.

Halliwell, B. and Gutteridge, J.M.C. 1998. Antioxidant defences. In: Halli-well B, Gutteridge, J.M.C., editors Free Radicals in Biology and Medicine; Oxford: University Press (London), pp: 155-158.

Kalthur, G., Raj, S., Thiyagarajan, A., Kumar, S., Kumar, P., and Adiga, S.K. 2011. Vitamin E supplementation in semenfreezing medium improves the motility and protects sperm from freeze-thawinduced DNA damage. Journal of Dairy Science. 95 (3):1149-51.

Kim, J.G. and Parthasarathy, S. 1998. Spermatozoa are protected by various antioxidants and antioxidant enzymes in the seminal plasma or in spermatozoa itself to prevent oxidative damage. Reproductive Endocrinology. 16 (4): 235-239.

Lobascio, A.M., De Felici, M., Anibaldi, M., Greco, P., Minasi, M.G., and Greco, E. 2015. Involvement of seminalleukocytes, reactive oxygen species, and sperm mitochondrial membrane potential in the DNA damage of the human spermatozoa. Fertility and Sterility. 94(4): 15411543.

Michael, A., Alexopoulos, C., Pontiki, E.A., Hadjipavlou-Litina, D., Saratsis, P. and Boscos, C. 2007. Effect of antioxidant supplementation on semen quality and reactive oxygen species of frozenthawed canine spermatozoa. Theriogenology. 68: 204-212.

Satorre, M.M., Breininger, E., Beconi, M.T., Beorlegui, N.B. 2007. $\alpha$-Tocopherol modifies tyrosine phosphorylation and 
capacitation-like state of cryopreserved porcine sperm. Theriogenology. 68: 958-65.

Sharma, R.K. and Agrawal, A. 1996. Role of reactive oxygen species in male infertility. Urology. 48:835-850.

Sikka, S.C. 1996. Oxidative stress and role of antioxidants in normal and abnormal sperm function. Frontiers in Bioscience. 1: 567-670.

Sikka, S.C., Green, A.G., Chauhan, V. and Kalra, V.K. 1982. Proteoliposomcs interaction with human erythrocyte membrane - functional implantation of gamma glutamyl transepeptidase. Biochemistry. 21: 2356-2366.

Silva, P.F.N. 2006. Physiology of peroxidation process in mammalian sperm. PhD Thesis. Utrecht University. Ridderprint, Ridderkerk., pp.5-36.

Sinha, M.P., Sinha, A.K., Singh, B.K. and Prasad, R.L. 1996. The effect of glutathione on the motility, enzyme leakage and fertility of frozen goat semen. Animal reproduction science. 41: 237-243.

Surai, P.F., Blesbois, E., Grasseau, I., Chalah, T., Brillard, J.P., Wishart, G.J., Cerolini, S. and Sparks, N.H.C. 1998. Fatty acid composition, glutathione peroxidase and superoxide dismutase activity and total antioxidant activity of avian semen. Comp. Biochem. Physiol. B. 120: 527533.

Thuwanut, P., Chatdarong, K., Johannisson, A., Bergqvist, A.S., Söderquist, L. and Axnér, E. 2010. Cryopreservation of epididymal cat spermatozoa: effects of in vitro antioxidative enzymes supplementation and lipid peroxidation induction. Theriogenology. 73(8):107687.

Treulen, F., Uribe, P., Boguen, R., and Villegas, J.V. 2015. Mitochondrial permeability transition increases reactive oxygen species production and induces DNA fragmentation in human spermatozoa. Epub ahead of print. Feb 5. pii: $\operatorname{dev} 015$.

Urata, K., Narahara, H., Tanaka, Y., gashiru, T., Takayama, E. and Miyakaw, I. 2001. Effect of endotoxin-induced reactive oxygen species on sperm motility. Fertility and Sterility. 76: 163-166.

Watson, P.F. 1995. Recent development and concepts in cryo preservation of spermatozoa and assessment of their post thawing function, Reproduction fertile Dev. 7: 871-791.

\section{How to cite this article:}

Archana Sarangi, Anuradha Verma, Ram N. Patel, Adya P. Rath, Subhasish Sahu, Meenakshi Virmani and Pooja Devi. 2018. Vitamin E and Gluthathion as Antioxidant in Liquid Preservation of Semen: A Review. Int.J.Curr.Microbiol.App.Sci. 7(04): 1680-1684. doi: https://doi.org/10.20546/ijcmas.2018.704.189 